\title{
Metallurgical Mechanism and Optical Properties of CuSnZnSSe Powders Using a 2-Step Sintering Process
}

\author{
Tai-Hsiang Liu, ${ }^{1}$ Fei-Yi Hung, ${ }^{1}$ Truan-Sheng Lui, ${ }^{1}$ and Kuan-Jen Chen ${ }^{2}$ \\ ${ }^{1}$ Department of Materials Science and Engineering, Center for Micro/Nano Science and Engineering, \\ National Cheng Kung University, Tainan 701, Taiwan \\ ${ }^{2}$ The Instrument Center, National Cheng Kung University, Tainan 701, Taiwan
}

Correspondence should be addressed to Fei-Yi Hung; fyhung@mail.ncku.edu.tw

Received 3 April 2014; Accepted 14 May 2014; Published 5 June 2014

Academic Editor: Liang-Wen Ji

Copyright (C) 2014 Tai-Hsiang Liu et al. This is an open access article distributed under the Creative Commons Attribution License, which permits unrestricted use, distribution, and reproduction in any medium, provided the original work is properly cited.

\begin{abstract}
$\mathrm{Cu}_{2} \mathrm{SnZn}(\mathrm{S}+\mathrm{Se})_{4}$ is an excellent absorber material for solar cells. This study obtained $\mathrm{Cu}_{2} \mathrm{SnZn}(\mathrm{S}+\mathrm{Se})_{4}$ powders through solid state reaction by the ball milling and sintering processes from elemental $\mathrm{Cu}, \mathrm{Zn}, \mathrm{Sn}, \mathrm{S}$, and Se without using either polluting chemicals or expensive vacuum facilities. Ratios of S/S + Se in CuSnZnSSe were controlled from 0 to 1 . The results showed that the 2-step sintering process $\left(400^{\circ} \mathrm{C}\right.$ for $12 \mathrm{hrs}$ and then $700^{\circ} \mathrm{C}$ for $\left.1 \mathrm{hr}\right)$ was able to stabilize the composition and structure of the CuSnZnSSe powders. The crystallized intensity of the CuSnZnS matrix decreased with increasing the Se content. Raising the Se content restrained the $\mathrm{SnS}$ phase and reduced the resistance of the absorber layer. In addition, Raman data confirmed that Se caused a Raman shift in the CuSnZnSSe matrix and enhanced the optical properties of the CuSnZnSSe powders. For the interface of CuSnZnSSe film and Mo substrate, Mo could diffuse into CuSnZnSSe matrix after $200^{\circ} \mathrm{C}$ annealing. The interface thermal diffusion of CuSnZnSSe/ZnS improved the effects of stack to enhance the stability of structure.
\end{abstract}

\section{Introduction}

The development of CZTS $\left(\mathrm{Cu}_{2} \mathrm{Zn}_{1} \mathrm{Sn}_{1} \mathrm{~S}_{4}\right)$ has been a subject of focus in recent years $[1,2]$. Due to the lower cost of $\mathrm{Zn}$ and Sn element compared with In and Ga in the CIGS system, CZTS is considered a potential substitute for CIGS in the future. In the literature [3-5], CZTS thin film has been formed in many ways such as cosputtering [3], electroplated deposition [4], and pulsed laser deposition (PLD) [5]. But the cost of manufacturing is high, so the development is slow.

In this research, we used mechanical milling on the solid powders to synthesize CZTSSe powders and it was lowcost with a stable structure. $\mathrm{Cu}, \mathrm{Zn}, \mathrm{Sn}$, and $\mathrm{S}$ have been used to form CZTS powders, but the low boiling point of $S$ [6] makes it hard to control the composition of CZTS when the $S$ vaporizes at higher temperatures. The boiling point of Se is higher than that of S, and Se can stabilize the CZTS powders. Therefore, this research controlled the $\mathrm{Cu}, \mathrm{Zn}$, and $\mathrm{Sn}=2: 1: 1$ at.\%, and then mixed $\mathrm{S}$ and $\mathrm{Se}$ in different ratios to combine with $\mathrm{Cu}, \mathrm{Zn}$, and $\mathrm{Sn}$ precursor to form the $\mathrm{Cu}_{2} \mathrm{SnZn}(\mathrm{S}+\mathrm{Se})_{4}$ powders. During mixing, a 2-step sintering process was performed $\left(400^{\circ} \mathrm{C}\right.$ for $12 \mathrm{hrs}$ controlled the concentrations of S and $\mathrm{Sn} ; 700^{\circ} \mathrm{C}$ for $1 \mathrm{hr}$ controlled the concentration of $\mathrm{Se}$ ) to adjust the ratios of $x=\mathrm{S} / \mathrm{S}+\mathrm{Se}$. The 2 -step sintering process is not only a continuous method, but also the metallurgical efficiency $[7,8]$ which helps to homogenize the compound powders. This study used the 2-step sintering process without using either polluting chemicals or expensive vacuum facilities to investigate the metallurgical mechanism of the CZTSSe powders. In addition, the morphology, crystalline structure, and optical properties of the CZTSSe powders were measured to examine the effect of Se addition. The effect of $200^{\circ} \mathrm{C}$ annealing in the interface diffusion of $\mathrm{ZnS} / \mathrm{CZTSSe} / \mathrm{Mo}$ structure was also explored in CZTSSe system.

\section{Experimental Procedure}

The $\mathrm{Cu}_{2} \mathrm{SnZn}(\mathrm{S}+\mathrm{Se})_{4}$ powders were synthesized using pure $\mathrm{Cu}, \mathrm{Zn}, \mathrm{Sn}, \mathrm{S}$, and Se powders. The atomic ratio of $\mathrm{Cu}: \mathrm{Zn}: \mathrm{Sn}:(\mathrm{S}+\mathrm{Se})$ was $2: 1: 1: 4$. The atomic ratio of 


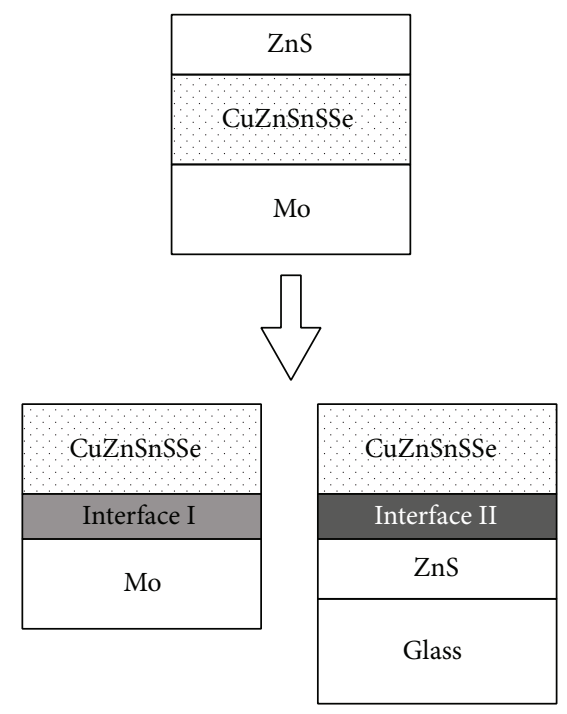

FIGURE 1: Interface I and interface II of ZnS/CZTSSe/Mo structure.

$\mathrm{Cu}: \mathrm{Zn}$ : $\mathrm{Sn}$ was fixed. Five atomic ratios containing pure $\mathrm{S}$, $\mathrm{S}: \mathrm{Se}=3: 1, \mathrm{~S}: \mathrm{Se}=1: 1, \mathrm{~S}: \mathrm{Se}=1: 3$, and pure Se were mixed to obtain 5 types of $\mathrm{Cu}_{2} \mathrm{SnZn}(\mathrm{S}+\mathrm{Se})_{4}$ powders. The ratio value was defined as $x=\mathrm{S} /(\mathrm{S}+\mathrm{Se})$.

The powders were milled for $1 \mathrm{hr}$ in molecular ratio inside a crucible and then sintered in a stove at $400^{\circ} \mathrm{C}$ for 12 hours (1st-step sintering). During this $400^{\circ} \mathrm{C}$ sintering, S, Se, and Sn turned to liquid state and combined with $\mathrm{Cu}$ and $\mathrm{Zn}$ to form compounds. After this, the $\mathrm{Cu}_{2} \mathrm{SnZn}(\mathrm{S}+\mathrm{Se})_{4}$ powders were sintered at $700^{\circ} \mathrm{C}$ for 1 hour (2nd-step sintering). The residual $\mathrm{S}$ and $\mathrm{Se}$ were vaporized from $\mathrm{Cu}_{2} \mathrm{SnZn}(\mathrm{S}+\mathrm{Se})_{4}$ powders. Finally, the powders were cooled to room temperature and the measurement of crystallization and optical properties was performed.

The morphology and crystalline structure of the powders were observed using SEM (Hitachi SU8000), TEM (JEOL JEM-1400), and XRD (Bruker AXS Gmbh, Karlsruhe, Germany). In addition, the compositions of the powders were determined using ICP (HEWLETT PACKARD 4500, JP) and EDS. Raman, reflection pattern and resistance of CZTSSe powders were measured to understand the contributions of $S$ and Se ratios $[6,9]$. Each analysis datum is the average of 4 test results.

In addition, the powder of $\mathrm{S}: \mathrm{Se}=1: 1$ was deposited by thermal evaporation and combined $\mathrm{ZnS}$ film ( $\mathrm{ZnS}$ film was obtained from aqueous solution method) and Mo substrate to form CZTSSe/Mo specimen and CZTSSe/ZnS/glass specimen (Figure 1). The interface diffusion mechanisms of $\mathrm{ZnS/CZTSSe/Mo} \mathrm{structure} \mathrm{were} \mathrm{detected} \mathrm{by} \mathrm{TEM} \mathrm{(JEOL}$ JEM-1400) with EDS before and after $200^{\circ} \mathrm{C}$ annealing to explore the interface characteristics.

\section{Results and Discussion}

The SEM morphologies of the five CZTSSe powders after the 2 -step sintering process are shown in Figure 2. The powders were particle-like and the agglomeration was not obvious after mechanical milling. EDS analysis showed that the S/S + Se ratio of powders complied with the proportion and the average particle size of the powders was $160 \sim 220 \mathrm{~nm}$. The powders could be applied for coating of devices and their morphologies were similar to the powders in the literature [4]. In addition, the CZTSSe powders were examined by XRD to identify the phase structure (Figure 3). It was found that the diffraction peak angle of the CZTSSe powders reduced slightly with increasing the content of Se. The main reason is that the atomic radius of Se is larger than $S$ [10]. Thus, Se atoms replacing $S$ would cause the lattice to expand. According to diffraction theory, $n \lambda=2 d \sin \theta$, we have good grounds for thinking that the addition of Se increased the value of $d$ and then reduced the value of $\theta$ in the CZTS system.

Notably, the combination of $\mathrm{S}$ and $\mathrm{Se}$ in the $\mathrm{Cu}-\mathrm{Zn}-\mathrm{Sn}$ matrix requires a stable sintering process. If the powders are only given the 1st-step sintering (without the 2nd step), the CZTS(S = 100\%) will not only have the CZTS main diffraction planes, but also have the SnS phase (Figure 4(a)). We attempted to extend our observation in the CZTSSe ( $\mathrm{S}=$ $50 \%$, Se $=50 \%$ ) system (only 1st-step sintering, Figure 4(b)). XRD diffractions proved clearly that some pure Se phases remained in the CZTSSe matrix, but no SnS phase was found. It is clear that both the addition of Se and the 2-step sintering process are able to improve the crystallization of the CZTSSe system.

The CZTSSe powders with a 2-step sintering process were compressed into the ingots and then their electrical resistance was measured using a 4-point probe analyzer. Figure 5 shows the electrical properties of the CZTSSe powders and the CZTS $(S=100 \%)$ powder has the highest electrical resistance. The electrical resistance of the CZTSSe (S : Se $=1: 1, x=0.5)$ powder and the CZTSe $(\mathrm{Se}=100 \%)$ powder were similar. Notably, the two CZTSSe powders with ratio $\mathrm{S}: \mathrm{Se}=3: 1$ $(x=0.75)$ and $\mathrm{S}: \mathrm{Se}=1: 3(x=0.25)$ had the lowest electrical resistance. These electrical properties were closely related to the chemical composition and the phase structure. It is clear that adding Se can reduce the electrical resistance of CZTSSe powders. For the $S: S e=3: 1(x=0.75)$ powder, an excess of $S$ combined with $\mathrm{Sn}$ to form SnS phase [10]. For the S: Se $=1: 3(x=0.25)$ powder, some residual Se could not enter the matrix. For this reason, their electrical resistance was lower than that of the other powders. Recent reports [11, 12] claim that the electrical resistance of CZTS powder systems has still not been explored. We have the experience in the electrical measurements of powders [13] and can confirm that SnS phase and Se in the CZTSSe powders are the main phases to affect the electrical properties.

The CZTSSe powders were subjected to Raman spectrum to observe their Raman shift characteristics. Figure 6 shows that Se addition caused a Raman shift in the CZTSSe powders (from 334.8 to $323.8 \mathrm{~cm}^{-1}$ ) and the shift frequency increased with increasing Se content. Notably, a CZTSe (Se $=100 \%)$ peak was not found at $323 \sim 335 \mathrm{~cm}^{-1}$, but a ZnSe peak was found at $240.8 \mathrm{~cm}^{-1}$. In a word, adding Se affected the Raman results and the CZTSe $(\mathrm{Se}=100 \%)$ powder revealed a different Raman spectrum from the CZTSSe powders. The two main reasons are as follows: (1) adding Se prevented Sn 


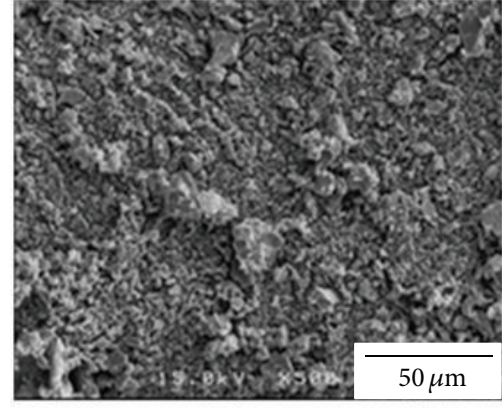

(a)

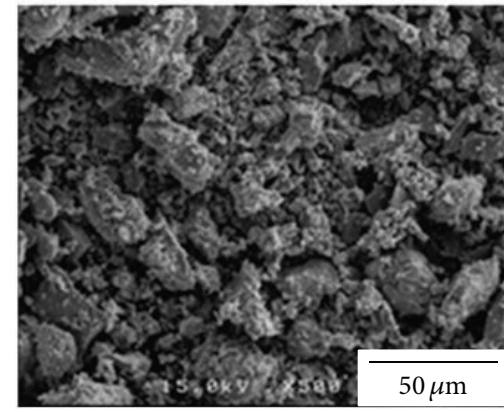

(b)

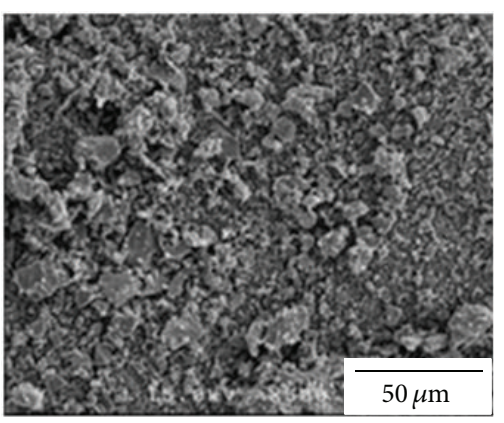

(c)

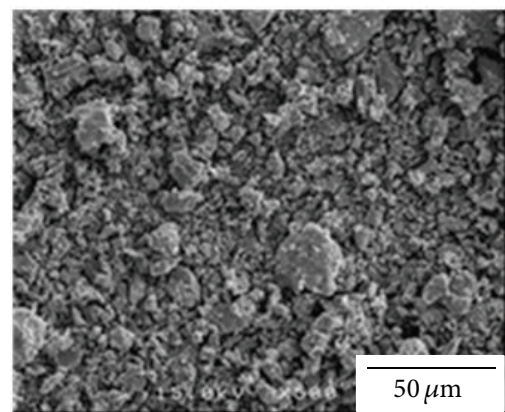

(d)

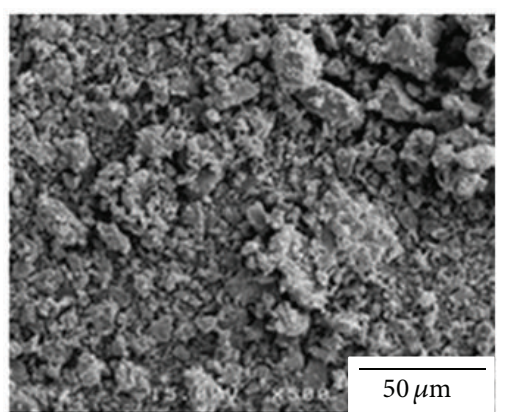

(e)

Figure 2: Morphology of CZTSSe powders. (a) CZTSe (Se: 100\%, $x=0$ ), (b) CZTSSe (S: $25 \%+$ Se: 75\%, $x=0.25)$, (c) CZTSSe (S: 50\% + Se: $50 \%, x=0.5)$, (d) CZTSSe (S: 75\% +Se: 25\%, $x=0.75$ ), and (e) CZTS (S: $100 \%, x=1$ ).

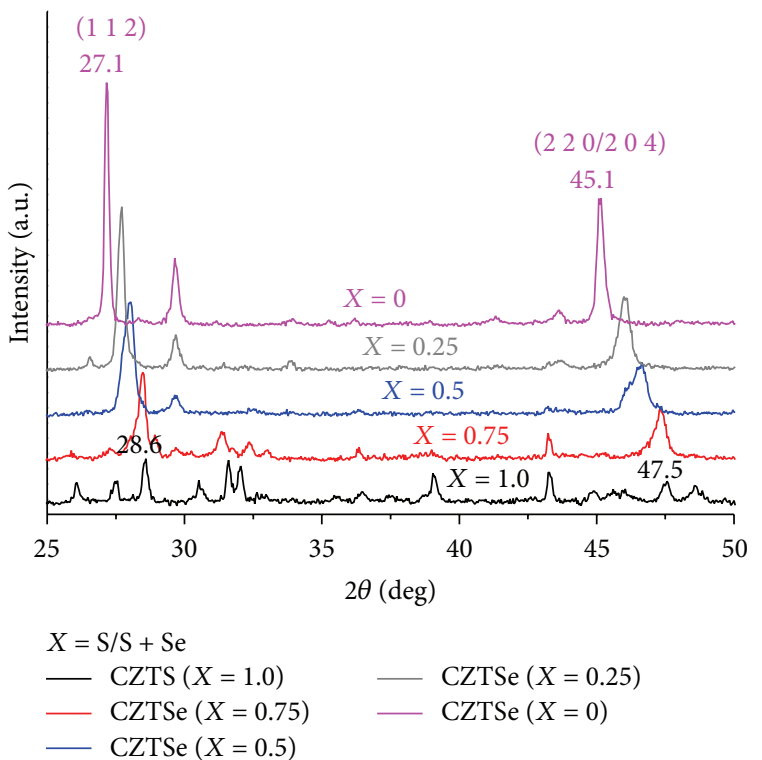

Figure 3: XRD of five CZTSSe powders.

from binding with $\mathrm{S}$ to form $\mathrm{SnS}$ phase to cause structural defects and (2) some Se would inflate the lattice to cause a Raman shift in the CZTSSe powders. In a word, the random distribution of $\mathrm{S}$ and Se atoms in the lattice resulted in the fluctuations in the masses and force constants in the neighborhood $[14,15]$. Because the electrical and optical properties of the CZTSSe ( $\mathrm{S}: \mathrm{Se}=1: 1$ ) powders were improved, CZTSSe ( $\mathrm{S}: \mathrm{Se}=1: 1)$ was selected for TEM analysis.

Figure 7 shows the TEM observations of the CZTSSe $(S: S e=1: 1)$ powder. The CZTSSe powder was agglomerated and the single particle size was about $160 \sim 220 \mathrm{~nm}$. According to EDS results and comparing with the literature $[11,12]$, the ratio $\mathrm{S}: \mathrm{Se}=13: 15$ (Figure $7(\mathrm{a})$ ) approached the atomic ratio of $1: 1$. In addition, a bright field image (Figure $7(\mathrm{a})$ ) and a dark field image (Figure 7(b)) reveal that the overlapping of powders and Se was uniform in the matrix. Figure 7(c) shows that the CZTSSe powder had a tetragonal structure which grew in the direction of $C$-axis.

Figure 8 shows the reflection percentage of the CZTSSe powders. We can be fairly certain that the CZTS ( $S=100 \%)$ powder had the highest reflection percentage. As Se was added, the reflection percentage decreased. Judging from the above, for continuous wavelength light, the absorption of the CZTSSe powder was better than that of the CZTS powder with pure sulfur. From the present data and a previous paper, it is clear that adding Se increases the absorption edge $(\mathrm{nm})$ in the S-Se mixed system and then raises the reflection percentage. Therefore, when the wavelength is higher than the absorption edge, the absorption of CZTSe or CZTSSe is higher than CZTS powder with pure sulfur. Figure 8 shows that the wavelength of the absorption edge of the CZTS powder was about $300 \mathrm{~nm}$; thus, the reflection $(R \%)$ decreased significantly below $300 \mathrm{~nm}$ in wavelength.

The CZTSSe ( $\mathrm{S}: \mathrm{Se}=1: 1)$ powders were deposited on Mo substrate by thermal evaporation. Both as-deposed and 


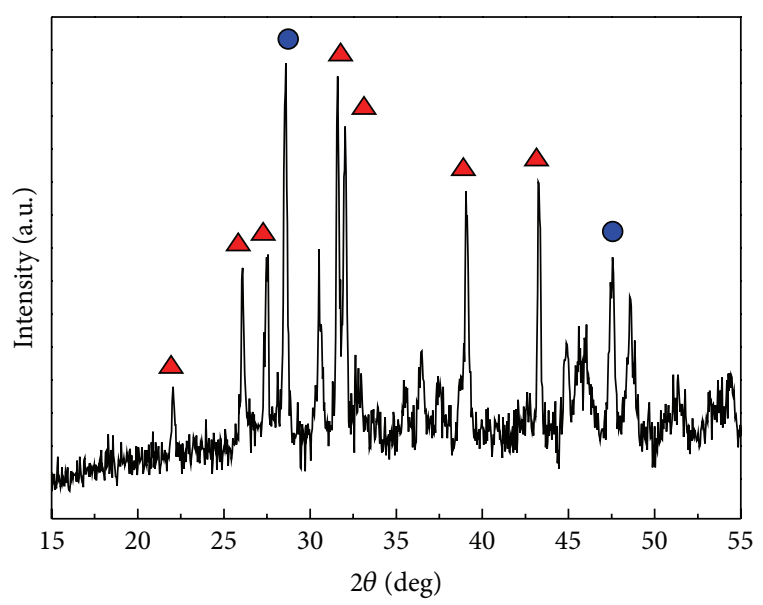

- CZTS (S: $100 \%)$

$\triangle \mathrm{ZnS}$

(a)

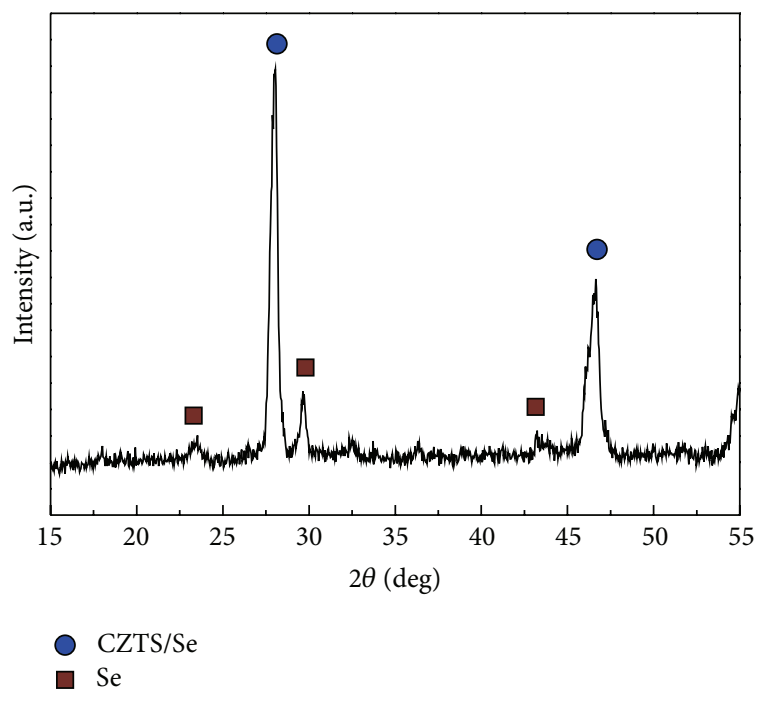

(b)

FIGURE 4: (a) XRD of CZTS(S: 100\%), (b) XRD of CZTSSe (S: $50 \%$, Se: $50 \%)$.

annealed CZTSSe/Mo structures were detected by TEM [1619]. According to Figure 1, the interface I was observed in Figures 9 and 10. In fact, the Mo atom had diffused into CZTSSe matrix due to thermal diffusion induced by thermal evaporation and the concentration of Mo in the surface of CZTSSe film was about 1.5 at.\%. After annealing, the concentration of Mo increased in the CZTSSe film and the zone near Mo substrate that had formed a continuous structure (EDS2 EDS3) from network structure. No doubt the CZTSSe film had the pollution of Mo atoms and it still had a tetragonal structure (see the pattern of Figure 10). The same observation applies to interface II of CZTSSe/ZnS/Glass structure (Figure 1). In Figure 11, the CZTSSe film (S:Se $=1: 1)$ of thermal evaporation was deposited on $\mathrm{ZnS}$ film. The CZTSSe film represented a stacking morphology, which associated with the lower thermal conductivity of

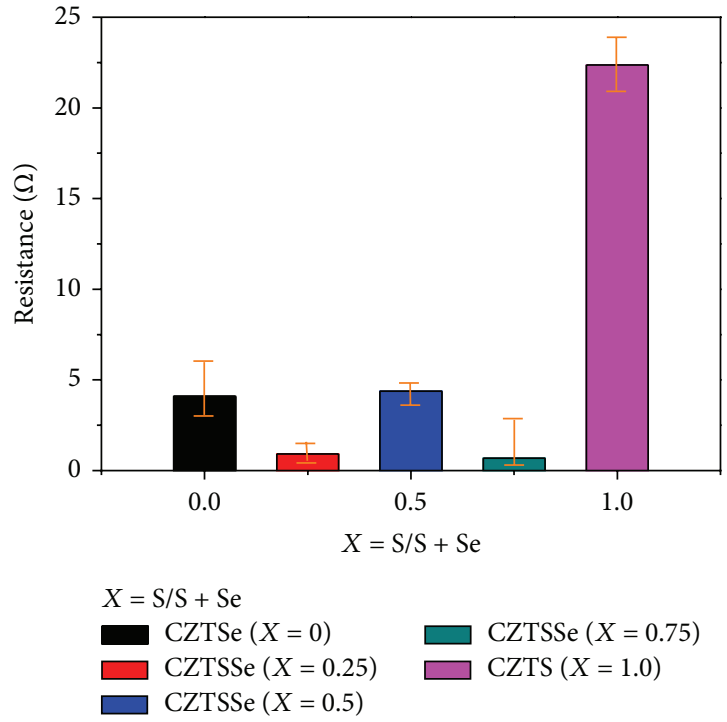

FIGURE 5: Resistance of five CZTSSe powders.

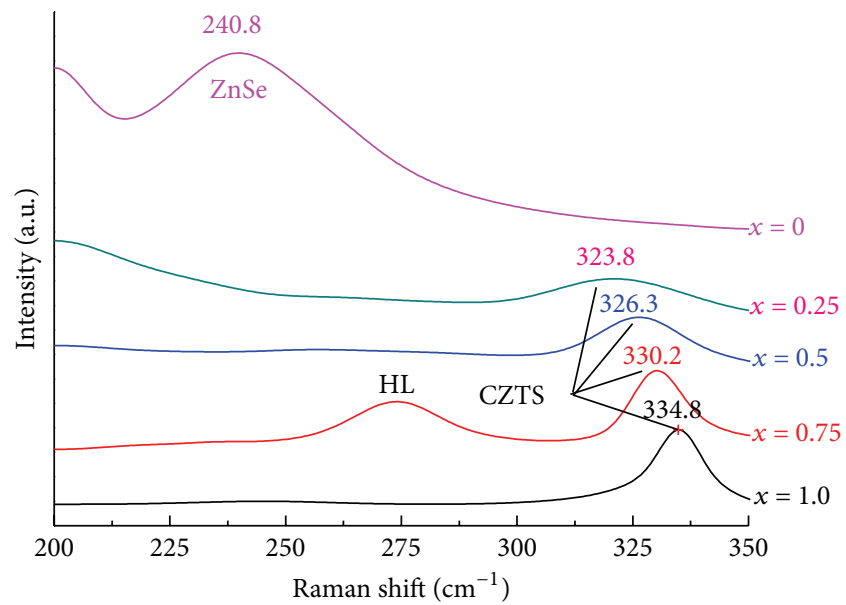

$X=\mathrm{S} / \mathrm{S}+\mathrm{Se}$
$-\operatorname{CZTS}(X=1.0)$
$-\operatorname{CZTSSe}(X=0.75) \quad$ CZTSSe $(X=0.25)$
$-\operatorname{CZTSe}(X=0)$

Figure 6: Raman of five CZTSSe powders.

$\mathrm{ZnS} /$ glass substrate. After annealing, the crystallization of CZTSSe film was improved to enhance the structural stability (Figure 12).

In the past, each laboratory had focused on the solar cell design for power performance. In fact, the interface of the structure is significant to affect the results of power performance. Results of this study can provide the interfacial properties of the solar cell design to assist in understanding the relationship between the power performance and materials. 


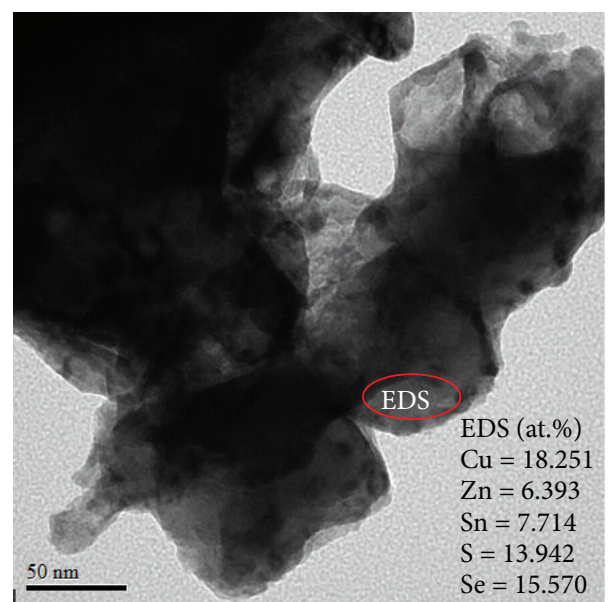

(a)

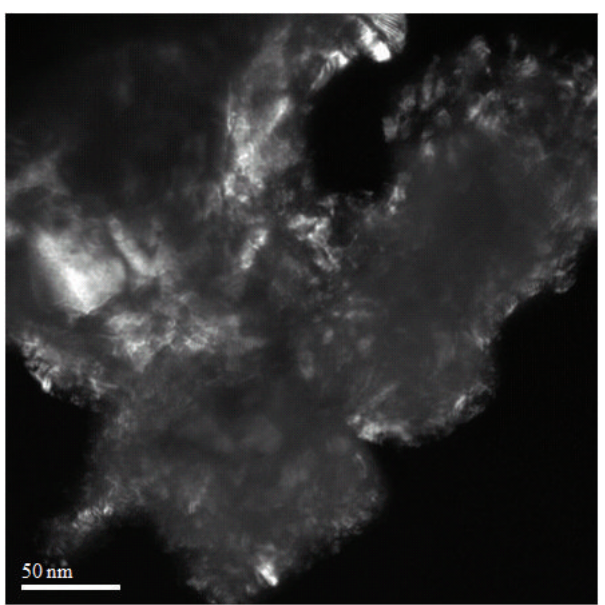

(b)

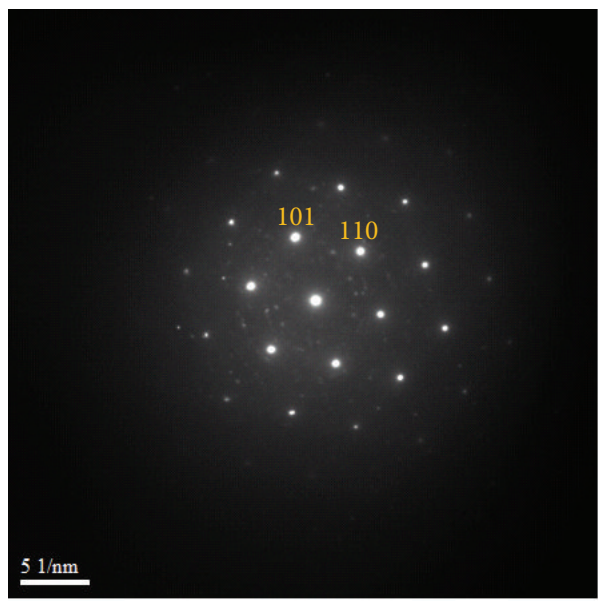

(c)

FIgURE 7: TEM observations of CZTSSe powders (S: $\mathrm{Se}=13: 17$ at atomic ratio). (a) Bright field image with EDS data, (b) dark field image, and (c) SAED of CZTSSe powders.

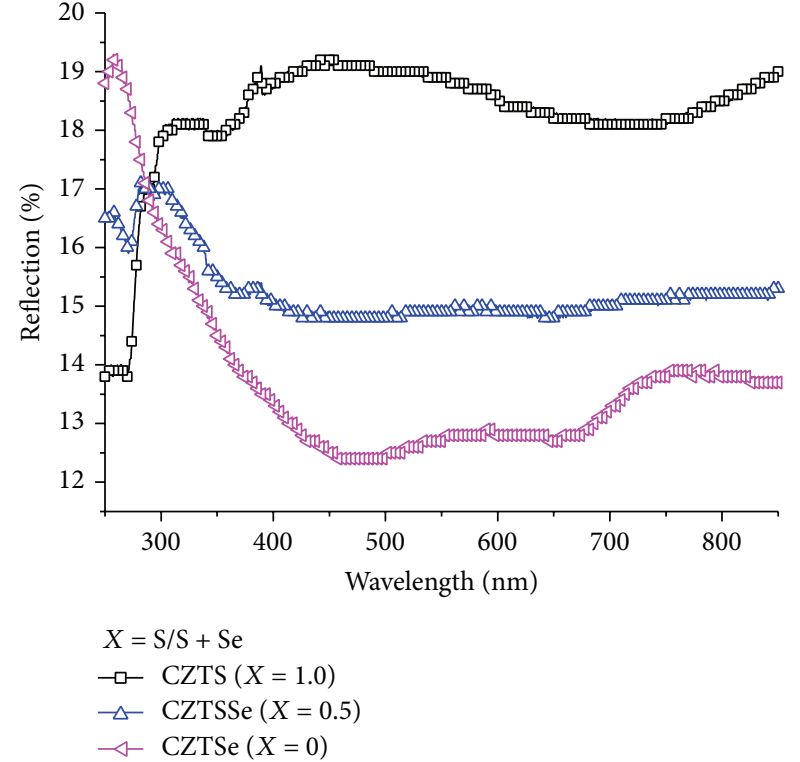

FIGURE 8: Absorption-reflection detection of different ratio in CZTSSe $\left(\mathrm{CZTS}_{x} \mathrm{Se}_{1-x}, X=1.0,0.5,0\right)$.

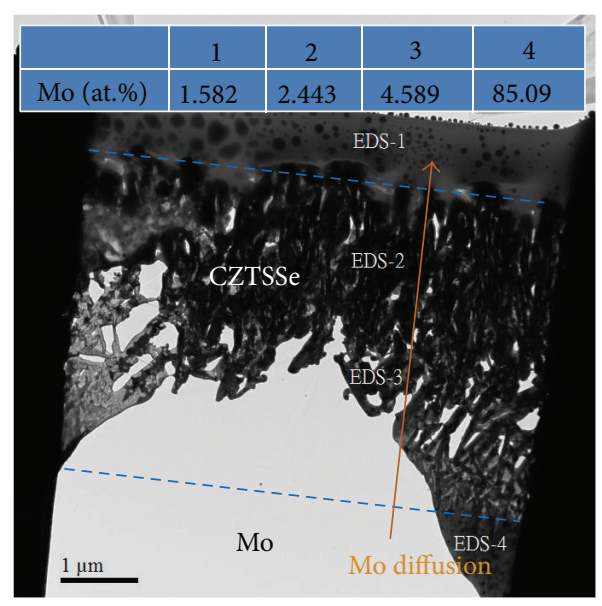

FIGURE 9: Interface observation of CZTSSe/Mo structure before annealing.

\section{Conclusion}

Adding Se stabilized the CZTSSe phase structure. It not only improved the electrical properties, but also caused obvious shift peaks in the Raman spectrum. In addition, the absorption of the CZTSSe powder was higher than the CZTS powder.

The five-element CZTSSe powder matrix was a tetragonal crystal. Both the addition of Se and the 2-step sintering process were able to improve the crystallization. After annealing, the CZTSSe/Mo structure had an obvious thermal diffusion of Mo atoms and the stacking of CZTSSe/ZnS structure was improved. The effects can improve the design and application of the solar cells. 


\begin{tabular}{|c|c|c|c|c|c|c|}
\hline EDS & 1 & 2 & 3 & 4 & 5 & 6 \\
\hline Mo (at.\%) & 83.491 & 69.177 & 65.721 & 12.698 & 10.149 & 8.273 \\
\hline
\end{tabular}
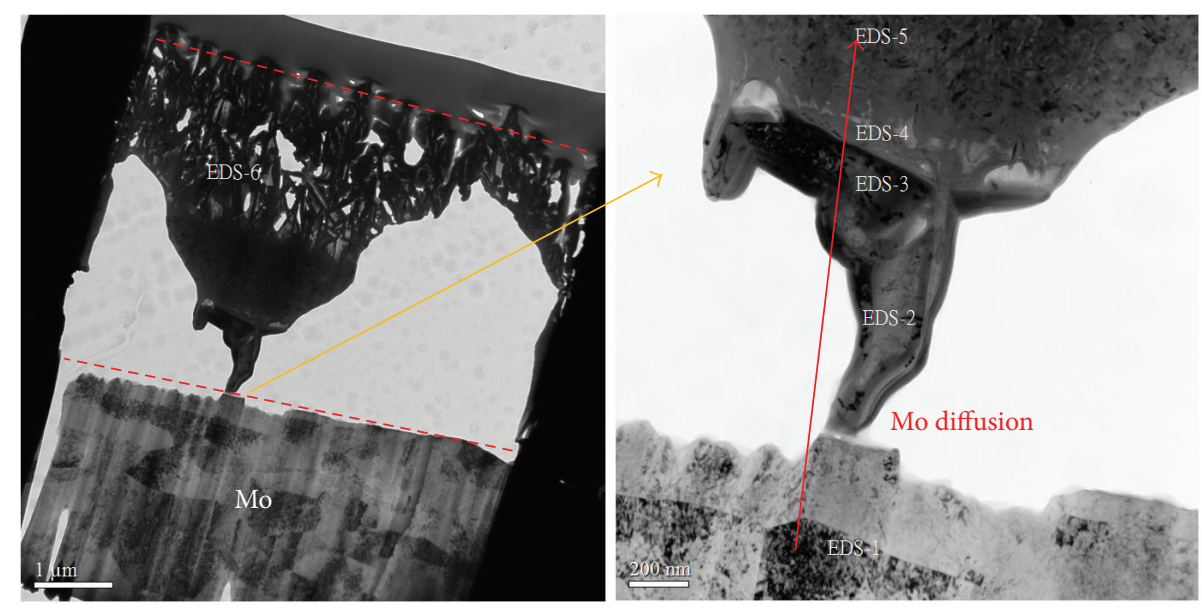

FIGURE 10: Interface characteristic of CZTSSe/Mo structure after annealing.
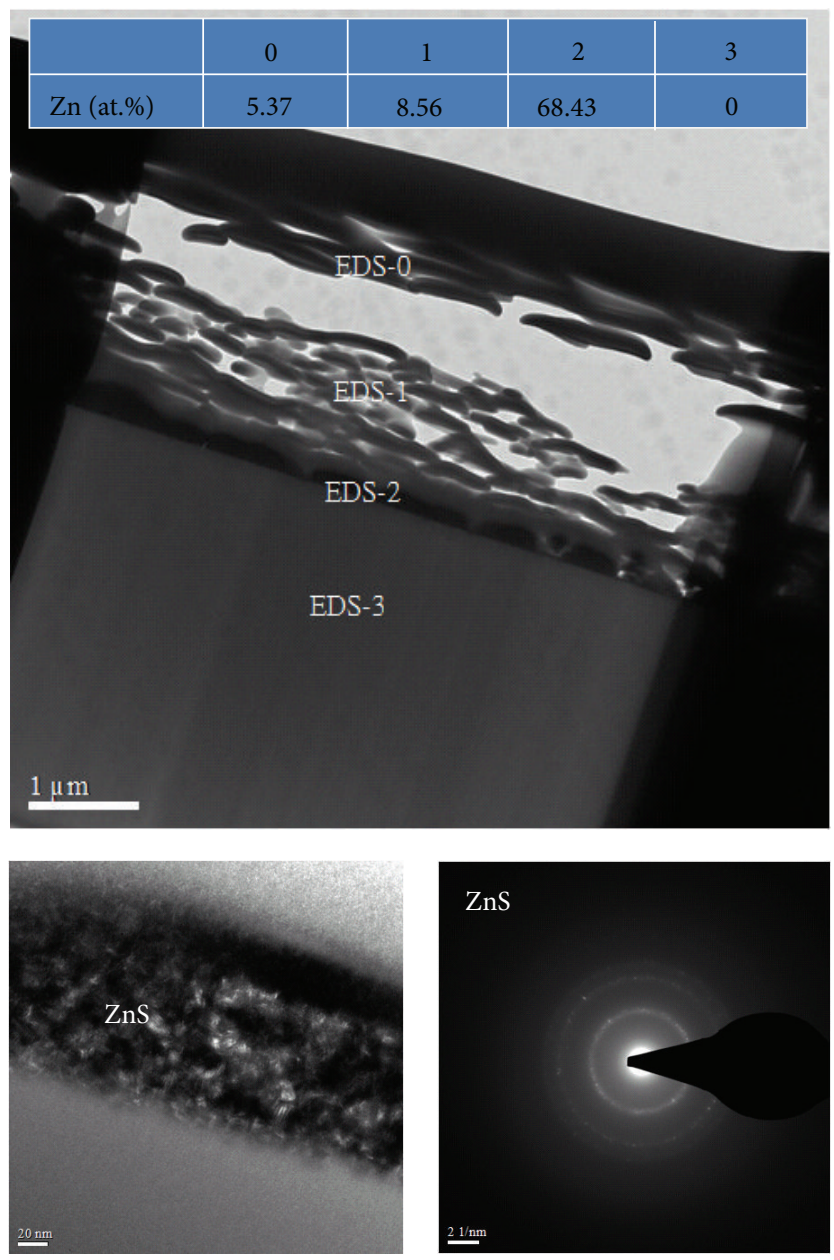

FIGURE 11: Interface observation of CZTSSe/ZnS structure before annealing. 

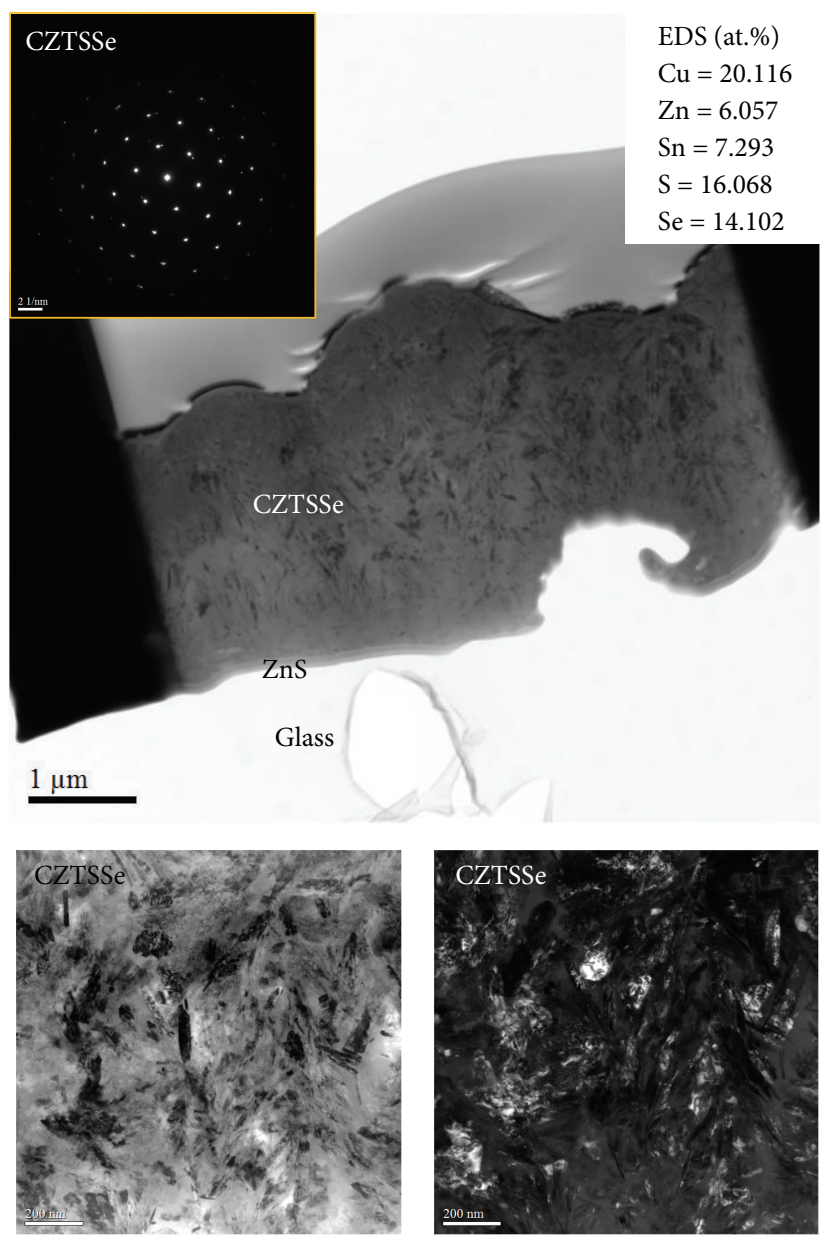

FIGURE 12: Crystallization of CZTSSe/ZnS structure after annealing.

\section{Conflict of Interests}

The authors declare that there is no conflict of interests regarding the publication of this paper.

\section{Acknowledgments}

The authors are grateful to National Cheng Kung University and NSC 102-2221-E-006-061 for the financial support.

\section{References}

[1] A. V. Moholkar, S. S. Shinde, A. R. Babar et al., "Synthesis and characterization of $\mathrm{Cu}_{2} \mathrm{ZnSnS}_{4}$ thin films grown by PLD: solar cells," Journal of Alloys and Compounds, vol. 509, no. 27, pp. 7439-7446, 2011.

[2] Y. Wang and $\mathrm{H}$. Gong, " $\mathrm{Cu}_{2} \mathrm{ZnSnS}_{4}$ synthesized through a green and economic process," Journal of Alloys and Compounds, vol. 509, no. 40, pp. 9627-9630, 2011.

[3] T. Prabhakar and N. Jampana, "Effect of sodium diffusion on the structural and electrical properties of $\mathrm{Cu}_{2} \mathrm{ZnSnS}_{4}$ thin films," Solar Energy Materials \& Solar Cells, vol. 95, no. 3, pp. 1001-1004, 2011.
[4] K. Tanaka, Y. Fukui, N. Moritake, and H. Uchiki, "Chemical composition dependence of morphological and optical properties of $\mathrm{Cu}_{2} \mathrm{ZnSnS}_{4}$ thin films deposited by sol-gel sulfurization and $\mathrm{Cu}_{2} \mathrm{ZnSnS}_{4}$ thin film solar cell efficiency," Solar Energy Materials \& Solar Cells, vol. 95, no. 3, pp. 838-842, 2011.

[5] L. Sun, J. He, H. Kong, F. Yue, P. Yang, and J. Chu, "Structure, composition and optical properties of $\mathrm{Cu}_{2} \mathrm{ZnSnS}_{4}$ thin films deposited by Pulsed Laser Deposition method," Solar Energy Materials \& Solar Cells, vol. 95, no. 10, pp. 2907-2913, 2011.

[6] A. Nagaoka, K. Yoshino, H. Taniguchi, T. Taniyama, and H. Miyake, "Preparation of $\mathrm{Cu}_{2} \mathrm{ZnSnS}_{4}$ single crystals from $\mathrm{Sn}$ solutions," Journal of Crystal Growth, vol. 341, no. 1, pp. 38-41, 2012.

[7] C.-H. Wang, F.-Y. Hung, T.-S. Lui, and L.-H. Chen, "The chargedischarge characteristics of woody carbon modified with $\mathrm{Fe}_{3} \mathrm{O}_{4}$ nano phase using the hydrothermal method," Materials Transactions, vol. 51, no. 1, pp. 186-191, 2010.

[8] Z.-S. Hu, F.-Y. Hung, S.-J. Chang et al., "Effects of Ag nanoshape and AgGa phase in Ag-Si nanostructure using 2-step etching process," Journal of Alloys and Compounds, vol. 509, no. 3, pp. 758-763, 2011.

[9] P. K. Sarswat, M. Snure, M. L. Free, and A. Tiwari, "CZTS thin films on transparent conducting electrodes by electrochemical technique," Thin Solid Films, vol. 520, no. 6, pp. 1694-1697, 2012. 
[10] M. Kauk, K. Muska, M. Altosaar et al., "Effects of sulphur and tin disulphide vapour treatments of $\mathrm{Cu} 2 \mathrm{ZnSnS}(\mathrm{Se}) 4$ absorber materials for monograin solar cells," Energy Procedia, vol. 10, pp. 197-202, 2011.

[11] G. Zha, W. Jie, T. Tan, and X. Wang, "Effect of surface treatments on the electrical and optical properties of CdZnTe single crystal," Nuclear Instruments and Methods in Physics Research A: Accelerators, Spectrometers, Detectors and Associated Equipment, vol. 566, no. 2, pp. 495-499, 2006.

[12] D. B. Mitzi, O. Gunawan, T. K. Todorov, K. Wang, and S. Guha, "The path towards a high-performance solution-processed kesterite solar cell," Solar Energy Materials \& Solar Cells, vol. 95, no. 6, pp. 1421-1436, 2011.

[13] K. J. Chen, F. Y. Hung, S. J. Chang, and Z. S. Hu, "The crystallized mechanism and optical properties of sol-gel synthesized $\mathrm{ZnO}$ nanowires," Journal of the Electrochemical Society, vol. 157, no. 3, pp. H241-H245, 2010.

[14] M. Grossberg, J. Krustok, J. Raudoja, K. Timmo, M. Altosaar, and T. Raadik, "Photoluminescence and Raman study of $\mathrm{Cu}_{2} \mathrm{ZnSn}\left(\mathrm{Se}_{\mathrm{x}} \mathrm{S}_{1-\mathrm{x}}\right)_{4}$ monograins for photovoltaic applications," Thin Solid Films, vol. 519, no. 21, pp. 7403-7406, 2011.

[15] R. Bacewicz, W. Gebicki, and J. Filipowicz, "Raman scattering in $\mathrm{CuInS}_{2 \mathrm{x}} \mathrm{Se}_{2(1-\mathrm{x})}$ mixed crystals," Journal of Physics: Condensed Matter, vol. 6, no. 49, article 003, pp. L777-L780, 1994.

[16] N. M. Shinde, R. J. Deokate, and C. D. Lokhande, "Properties of spray deposited $\mathrm{Cu}_{2} \mathrm{ZnSnS}_{4}$ (CZTS) thin films," Journal of Analytical and Applied Pyrolysis, vol. 100, pp. 12-16, 2013.

[17] S. W. Shin, J. H. Han, C. Y. Park, A. V. Moholkar, J. Y. Lee, and J. H. Kim, "Quaternary $\mathrm{Cu}_{2} \mathrm{ZnSnS}_{4}$ nanocrystals: facile and low cost synthesis by microwave-assisted solution method," Journal of Alloys and Compounds, vol. 516, pp. 96-101, 2012.

[18] N. M. Shinde, P. R. Deshmukh, S. V. Patil, and C. D. Lokhande, "Aqueous chemical growth of $\mathrm{Cu}_{2} \mathrm{ZnSnS}_{4}$ (CZTS) thin films: air annealing and photoelectrochemical properties," Materials Research Bulletin, vol. 48, no. 5, pp. 1760-1766, 2013.

[19] H. Yoo, J. Kim, and L. Zhang, "Sulfurization temperature effects on the growth of $\mathrm{Cu}_{2} \mathrm{ZnSnS}_{4}$ thin film," Current Applied Physics, vol. 12, no. 4, pp. 1052-1057, 2012. 

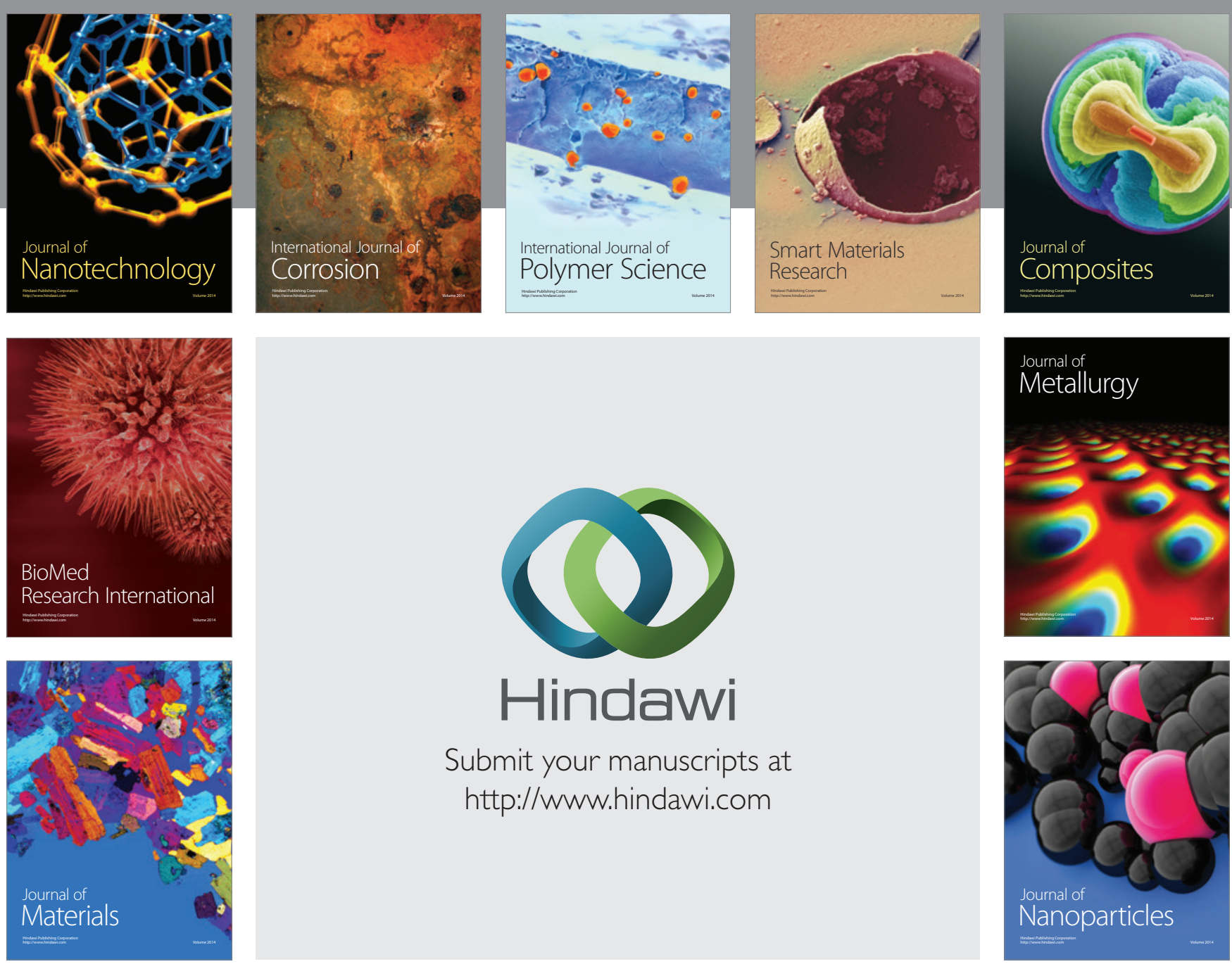

Submit your manuscripts at http://www.hindawi.com
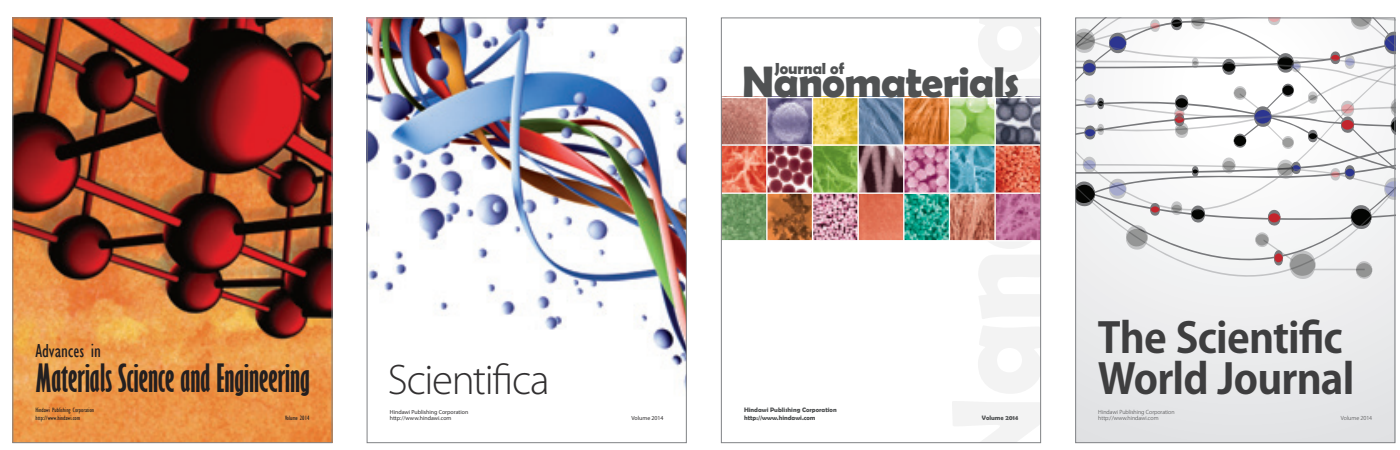

\section{The Scientific World Journal}
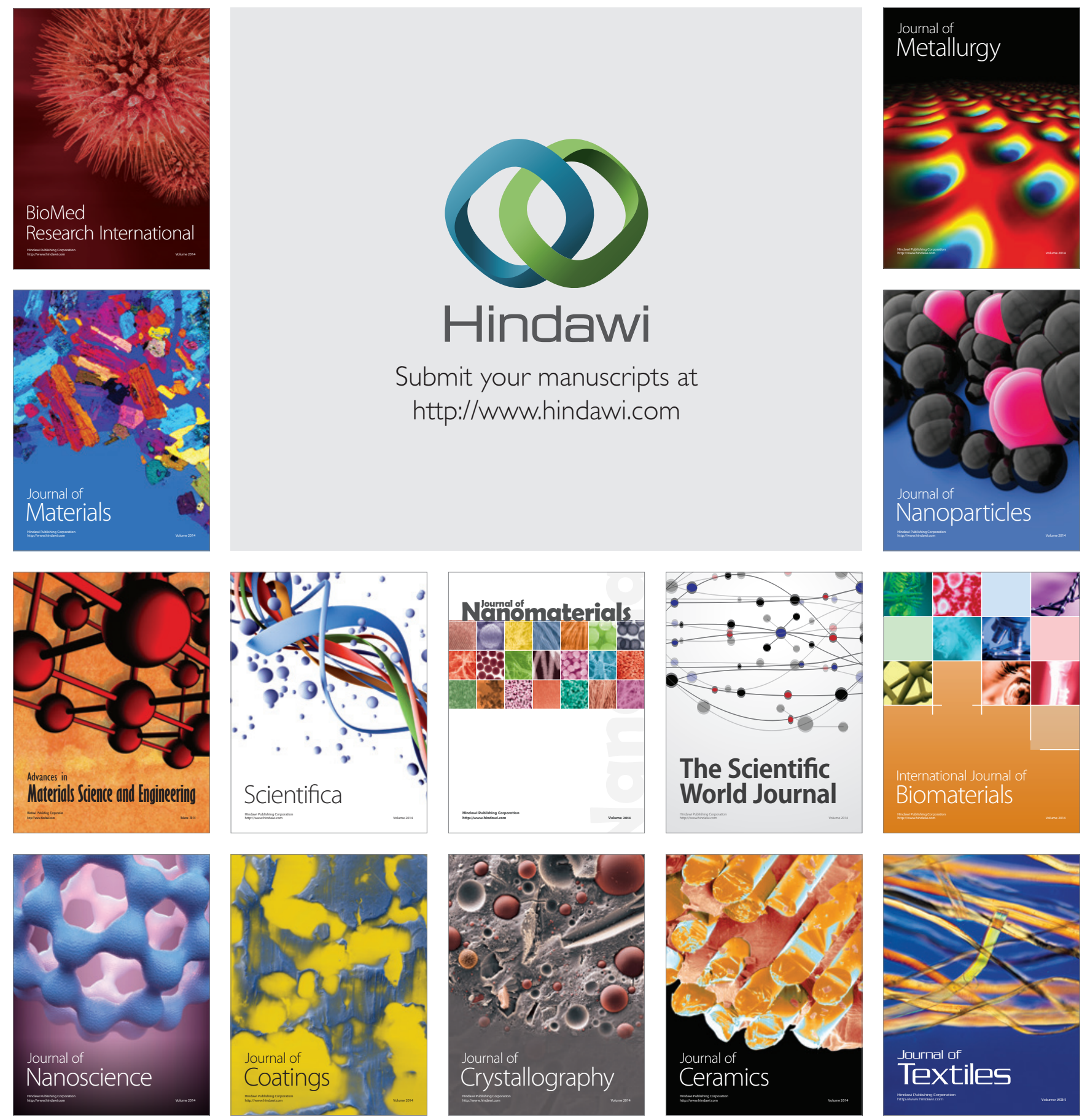